\title{
Interview with the Hon. Ken Wyatt: improving Indigenous health outcomes from a political viewpoint
}

Ken Wyatt ${ }^{a, b}$

a Minister for Indigenous Health and Minister for Aged Care, Australian Government, Canberra, ACT

b Corresponding author: Minister.Wyatt@health.gov.au

\section{Article history}

\section{Publication date: October 2017}

Citation: Wyatt K. Interview with the Hon. Ken Wyatt: improving Indigenous health outcomes from a political viewpoint. Public Health Res Pract. 2017;27(4):e2741731. https://doi.org/10.17061/phrp2741731

\section{Key points}

- In the past 50 years, there have been significant achievements in how health services for Indigenous people are delivered and who has control of these services

- Research is increasingly being done in partnership with Indigenous researchers and communities, with greater acknowledgement of the socio-economic, cultural and environmental factors that affect Indigenous health

- One knowledge gap in Indigenous health is understanding the social and emotional wellbeing of young Indigenous people, particularly drivers of suicide and resilience

\section{Abstract}

In 2017, Australia celebrates 50 years since the 1967 referendum, when more than $90 \%$ of Australians voted to amend the constitution to allow the national government to create laws for Indigenous people and include them in the census. We spoke with the Honourable Ken Wyatt, the Minister for Indigenous Health and the Minister for Aged Care, about what has occurred over the past 50 years in Indigenous health from a political perspective, and what we have learnt to improve health outcomes in the future.

\section{Interview}

Q: A lot has changed in Indigenous health over the past 50 years, with some significant gains made - as well as opportunities squandered - in improving health outcomes. What do you see as the most important developments in Australia that have contributed to improving the health of Aboriginal and Torres Strait Islander people since the 1967 referendum?

A: Over the past 50 years, we have seen significant milestones achieved in funding for Aboriginal and Torres Strait Islander health, how health services are delivered and who has control of these services.

In 1972, the Department of Aboriginal Affairs was created, with dedicated funding for Aboriginal health. Although this funding went to state jurisdictions, this was an important milestone because it was a commitment by the Commonwealth of Australia to do something about the health of Aboriginal people in rural and remote Australia.

At the same time, two seminal medical services were being established: the Redfern Aboriginal Medical Service in Sydney, New South Wales, and the Derbarl Yerrigan Health Service (originally the Perth Aboriginal Medical Service) in Western Australia. Although they were focused on primary health care, they became politically active in bringing to the fore key issues relating to Aboriginal and Torres Strait Islander people's lack of access to good healthcare.

The medical services also identified trends in diseases and the need for health systems to be receptive to the total patient journey for Aboriginal and Torres Strait Islander people. Their political lobbying resulted in increased funding, which led to the establishment of the Aboriginal community 
controlled health services that we now take for granted across this nation.

Q: How did the landscape of Indigenous healthcare change in response to the success of Aboriginal community controlled health services?

A: The establishment of the Aboriginal medical services changed the landscape in how jurisdictions dealt with Aboriginal communities. A number of influential figures, such as Naomi Mayers, Pat Delaney, Ted Wilkes, Fred Hollows and so many others who ultimately came on board, were not afraid to challenge state and territory ministers within their own communities. Nationally, they also highlighted the incredible gaps that Aboriginal people were experiencing and they lobbied heavily with the federal government until programs were put in place - for example, ensuring that a proportion of funding from the National Health and Medical Research Council is dedicated to Aboriginal health research.

The other important aspect was the development of leadership that evolved from the growth of Aboriginal medical services. Many important Aboriginal leaders and health practitioners began their careers in the Aboriginal medical services, and this grew the capacity of Aboriginal and Torres Strait Islander workers in a way that we had not seen before.

$\mathbf{Q}$ : There's a sense that being in control is very important; how does this translate to control over research?

A: A telling example that I remember was a conference in Alice Springs, in which the Aboriginal people attending walked out. Later, we held a meeting and talked about the papers that were presented and the concern that researchers were not translating their research to change on the ground.

We realised that we weren't going to be passive recipients anymore. We wanted to be in the leadership role. A turning point occurred when researchers and Aboriginal communities came to a common understanding about translational research being used to effect change on the ground, not to offer opportunities for researchers to publish papers on research that led to nowhere at all.

$\mathbf{Q}$ : There was obviously a turning point there, but do you sense there's still some way to go?

A: I think, from 1989 onwards, we've seen a change. The research that's being done now is often done in concert with Aboriginal researchers. The research work is taken back to those communities and the issues are talked through properly. And then there is a process for implementation, reform, lobbying, governance for change, etc., so I think we've come a long way.

Equally, we're seeing over the past 2 decades greater referencing made to social determinants of health and the logical framing of the reasons for needing to address education, employment, community safety, training and housing. That's really the incredible difference I've seen, not just established within the Department of Health, but also in interagency working parties that are looking at social determinants plus racism and their impact on the health of Aboriginal and Torres Strait Islander people.

$\mathbf{Q}:$ A criticism often made is that we produce too much evidence that describes the problems in Indigenous health, rather than conducting a sufficient number of studies that can help to solve them. Do you see sufficient ideas and innovations emerging from the research community?

A: We do in some elements of research that are being undertaken. For example, the work of the Vision 2020 Australia group and the work that Professor Hugh Taylor has done in improving eye health have been very successful in terms of the processes of engagement at all levels, the way in which services are delivered and the follow-up.

But one of the things we've not done well is identifying the jewels in the crown. All of those things that work on the ground in the community or within the health sector often make a difference because they are led by people who operate on a process of identifying a problem, seeing solutions, then working those solutions to an implementation phase with the community and with the Aboriginal staff. We need to identify all of the good things that are working and celebrate them.

$\mathbf{Q}$ : So where are the biggest knowledge gaps in Indigenous health currently?

A: I want to see more focus on youth and the many challenges facing young people in terms of social and emotional wellbeing. I'm also interested in understanding youth suicides among Aboriginal and Torres Strait Islander people, and some of the underlying issues that drive those.

In my electorate, I've spoken with police about what they see as the significant trends relating to youth suicide. They say it is failure - people have failed in a relationship, or been rejected several times for a job that they've applied for, or been turned down by a sporting team. Some young people have not been shown nor talked to about coping mechanisms to deal with rejection and failure. And I think we've got to do some work around that. It would be interesting to hear what young people say about how they perceive failure, how they cope with it and how they become resilient if they experience continued failure.

The other gap that I see is for ageing Aboriginal Australians, particularly relating to mental health.

I would also love to see front-end research that evaluates an initiative from the point it starts. Once an initiative starts, it would be great to see someone follow that initiative and write about the ideology, the process of establishment and then the steps of implementation that lead to change.

Q: In your time as a senior public servant in the fields of Aboriginal health and education, who were some of the key political figures who stood out to you?

A: The key players that I always remember well were Michael Wooldridge, who was minister for health for the Liberal Party of Australia from 1996 to 2001, and Graham 
Richardson, a senator for the Australian Labor Party, and minister for health from 1993 to 1994.

Graham Richardson used to ring me up during the time that he held the health portfolio and he would talk to me about issues, or just want to hear my thoughts. It was only a short period that he remained as the health minister, but had he stayed, I think he would have made a significant difference to the way the federal government was funding Aboriginal community controlled health services, and I think he would have turned his attention to the gaps in health for rural and remote Australia.

Q: What do you think makes a successful minister one who is going to achieve real, positive outcomes - for Aboriginal and Torres Strait Islander people?

A: You want ministers who are prepared to listen and who will receive advice from a department. But what I found with both Wooldridge and Richardson is that they absorbed the advice they were given, and then they made up their own minds afterwards. Both of them would leave a conversation and follow up with their agencies to turn that conversation into something much more meaningful.
Q: Finally, as a Minister, what types of research evidence have you found most useful and most compelling - what research puts you in the best position to make decisions about priorities and programs?

A: Over the past 45 years, I have endeavoured to be cognisant of all work that has been undertaken relating to Indigenous health and wellbeing. Many of the key messages have served me well and, while I don't want to focus on any research in particular, I have appreciated the breadth of the work undertaken by so many and I rely on their reflection of Indigenous voices.

\section{Acknowledgements}

The interview was conducted by the Editor-in-Chief of Public Health Research \& Practice, Don Nutbeam.

\section{Copyright: (c) (i) (2)}

(C) 2017 Wyatt. This article is licensed under the Creative Commons Attribution-NonCommercial-ShareAlike 4.0 International Licence, which allows others to redistribute, adapt and share this work non-commercially provided they attribute the work and any adapted version of it is distributed under the same Creative Commons licence terms. See: www.creativecommons.org/licenses/by-nc-sa/4.0/ 